\title{
Coping Behaviors and Collaboration among Staff of Multiple Occupation Classifications during Norovirus
}

\author{
Takae MACHIDA \\ Departments of Nursing, Faculty of Health \& Medical Care \\ Saitama Medical University \\ Saitama, Japan \\ t_machi@saitama-med.ac.jp \\ Hiroe YANAHARA \\ Department of Nursing, Faculty of Nursing \\ Shumei University \\ Chiba, Japan \\ yanahara@mailg.shumei-u.ac.jp
}

Sachie TOMITA

Departments of Nursing, Faculty of Health \& Medical Care

Saitama Medical University

Saitama, Japan

tomitas@saitama-med.ac.jp

\author{
Chihiro ASAKURA \\ Yujin-Home \\ Tokyo, Japan \\ eikochihiro@gmail.com
}

\author{
Kyoko SATO \\ Department of Nursing \\ Shoin University \\ Tokyo, Japan \\ 16s3026@g.iuhw.ac.jp \\ Hitomi SETOGUCHI \\ Department of Nursing, Faculty of Nursing \\ Shumei University \\ Chiba, Japan \\ setoguchi@mailg.shumei-u.ac.jp \\ Eiko SUZUKI \\ Department of Nursing \\ International University of Health and Welfare \\ Tokyo, Japan \\ eikosuzuki@iuhw.ac.jp
}

\begin{abstract}
In December 2012 a norovirus infection outbreak occurred in the Orthopedic Surgery Ward of Hospital A in Japan. This study aims to establish details of coping behaviors used by nurses, physicians, physiotherapists, and pharmacists of the facility, and examine the issues involved in infection control by team collaboration as well as the ways employed to deal with the infections. Participants in this study were thirty-seven medical professionals who were working in the Orthopedic Surgery Ward of Hospital $A$ at the time the infection outbreak occurred, and who were still working there when the interviews were conducted. Interviews were conducted from January to April 2015, and the data from the interviews were analyzed using the "Trend Search 2008" text mining software. As a result of the analysis it was found that the nurses primarily communicated information by passing messages to the nurses who took over the duty at shift changes, but did not pass on the information to staff in other occupations or to the ward as a whole. The nurses clearly remembered that the ward was closed and it was a difficult experience, but did not remember details of the patients they were in charge of. The physicians clearly remembered individual patients they were in charge of, but they were not aware of the situation and state throughout the ward. The findings suggest that this difference is due to the differences in the occupational nature and sense of values of the staff involved. It is also found that physiotherapists did not feel a sense of crisis about the
\end{abstract}

norovirus outbreak because they felt the patients in the ward appeared to be in better condition than patients in other wards, and that pharmacists lacked communication with staff in other occupations because they usually have heavy workloads. In concept mappings of physicians, physiotherapists, and pharmacists, the keyword <nurses> places in the center of the maps, and is linked to <information> and <report>. Because the nurse plays a central role to report information among the four occupations, nurses should be aware of and assigned to play the role to coordinate team collaboration.

Keywords; norovirus infection outbreaks, text mining, multidisciplinary collaboration

\section{INTRODUCTION}

In-hospital infections occur directly by person to person transmission, or through exposure to medical equipment and the environment. Specifically, exposed hosts such as patients with weakened immunity, premature infants, and elderly patients may be susceptible to in-hospital infections due to common pathogenic microbes as well as to microorganisms with weak infectivity. For this reason, it is stipulated that measures against in-hospital infections are required to be addressed by the entire medical institution, and not just by

This study is supported by MEXT/JSPS KAKENHI (Grant-in-Aid for Scientific Research (C), No.17K12177). We declare that we have no conflicts of interest. 
specific individual medical staff [1]. For the response to infection outbreaks in hospitals, a report has emphasized the importance of making arrangements for infection prevention, early detection, and an early response to outbreaks on a daily basis [2].

In the winter of 2012, large-scale food poisoning cases with more than 1,000 patients and in-hospital infections occurred frequently throughout Japan. In December 2012 the Orthopedic Surgery Ward of Hospital A was closed due to a norovirus infection epidemic, resulting in increases in costs, from the cancellations of regular hospitalizations and surgery, temporary discontinuation of rehabilitation of hospitalized patients, and extensions of hospitalizations. With the labor shortage arising from the norovirus infections among nurses and physicians, and the necessity of simultaneous disinfection of wards every two hours, personnel at the hospital had to cope with an extremely heavy additional workload. Worse, the infection placed patients at a serious disadvantage of suffering from infections other than the original illnesses, and placed unnecessary stress also on patients who were not infected. As described here, a norovirus infection seriously affects and disadvantages both patients and healthcare workers as well as it affects the hospital economic situation. Therefore, infection control is an important issue that must be addressed by all medical staff.

Previous studies have shown the importance of early detection and isolation to prevent norovirus infection outbreaks [3-7], suggesting that it is necessary for nurses who are in close contact with patients to pay attention to the possibility of the occurrence of norovirus infections, and take action to cope with the infection, promptly in collaboration with other staff. With this background, this study aimed to establish details of coping behaviors by nurses, physicians, physiotherapists, and pharmacists (four categories of hospital staff) of the affected facility, the characteristics of these behaviors by occupation and aspects of the cooperation among different occupations, and investigate how professionals of multiple classifications should cooperate with each other to control infections.

\section{METHODS}

\section{A. Participant Participants}

The total number of participants in this study was 37 professionals in 4 hospital staff categories (22 nurses, 4 physicians, 8 physiotherapists, and 3 pharmacists) who were working in the Orthopedic Surgery Ward of Hospital A, where a norovirus infection outbreak occurred in December, 2012 and who were still working there when the interviews were conducted.

\section{B. Survey period}

Interviews were conducted from January to April of 2015.

\section{Data collection}

To create an interview guide we conducted a preliminary survey of three nurses of the Orthopedic Surgery Ward of Hospital A in November 2014. From the narratives, we
Table 1 Headword and synonyms in the mined text

\begin{tabular}{|l||l|l|l|l|}
\hline Headword & $\begin{array}{c}\text { Synonym } \\
1\end{array}$ & $\begin{array}{l}\text { Synonym } \\
2\end{array}$ & $\begin{array}{c}\text { Synonym } \\
3\end{array}$ & $\begin{array}{c}\text { Synonym } \\
4\end{array}$ \\
\hline Vomiting & Vomiting & $\begin{array}{l}\text { Throwing } \\
\text { up }\end{array}$ & & \\
\hline Physician & Physician & $\begin{array}{l}\text { Physician } \\
\text { s }\end{array}$ & $\begin{array}{l}\text { Attending } \\
\text { physician }\end{array}$ & Doctor \\
\hline Nurse & Nurse & Nurses & $\begin{array}{l}\text { Nursing } \\
\text { staff }\end{array}$ & \\
\hline Norovirus & Norovirus & Noro & & \\
\hline
\end{tabular}

extracted elements and matters related to methods of communication and sharing of information, coping behaviors, and awareness of the spread of the infection. Based on this, we developed an interview guide for questions to ask about awareness and behaviors when the interviewees had confirmed the presence of symptoms in the patients. We conducted semistructured interviews using the interview guide in a location where privacy could be assured, and the interviews lasted about 20 minutes per person. The interviews were recorded with an electronic device, and transcribed with the consent of the interviewees.

\section{Data analysis}

Data from the interviews were analyzed using a text mining tool "Trend Search 2008" (SSRI). Text mining enables an objective analysis by visualizing large volumes of qualitative data as quantitative [8.9]. It also enables a scientific analysis because the relationship between and among words and terms can be visualized. The analysis of the text mining data was performed with the following procedures: (1) keyword association analysis to rank keywords according to frequency and variation; and (2) concept mapping analysis by mapping the extracted keywords in a two dimensional plane. In the keyword association analysis, the extracted keywords were organized into categories of unnecessary words, synonyms, and parts of speech. To handle synonyms such as "nurse", "sick nurse and nursing staff", "physician" and "medical doctor, medical staff, and doctor", "vomiting" and "throwing up", we decided to employ one as a headword to ensure consistency (Table 1). We ranked the keywords organized in descending order of importance based on the frequency of appearance and variation in the data (Table 2).

In the concept mapping analysis, keywords can be mapped onto a plane according to the $1^{\text {st }}$ to $200^{\text {th }}$ ranking of the importance based on the relations between the keywords. In the concept mapping in this study we used keywords from the $1^{\text {st }}$ to the $50^{\text {th }}$ place, and performed the analysis based on the distance between keywords and the thickness of connecting lines (links). The reason for using keywords up to the 50th keyword was that it was simple to distinguish the thickness and distance of the lines connecting the keywords, and that the keywords from the 51st place were determined to be of less importance because such keywords appeared in one or two sentences only. The text mining software has a function that instantaneously outputs original text with the keywords, which is extremely useful in qualitative research, when we search for a keyword (in the related text) [10]. In this study, we tried to understand the conditions the reported text sample describes 
Table 2 Demographic characteristics of participants

\begin{tabular}{|c|c|c|c|c|c|}
\hline & & $\mathrm{n}$ & $\begin{array}{c}\text { Mean age (years old) } \pm \\
\text { SD }\end{array}$ & $\begin{array}{c}\text { Mean length of } \\
\text { experience (years) } \pm \mathrm{SD}\end{array}$ & $\begin{array}{c}\text { Mean length of interviews } \\
\text { (Min.) } \pm \mathrm{SD}\end{array}$ \\
\hline Nurse & $\begin{array}{l}\text { Male } \\
\text { Female }\end{array}$ & $\begin{array}{c}2 \\
20\end{array}$ & $30.0 \pm 5.0$ & $7.8 \pm 5.3$ & $27.9 \pm 8.6$ \\
\hline Physician & $\begin{array}{l}\text { Male } \\
\text { Female }\end{array}$ & $\begin{array}{l}4 \\
0\end{array}$ & $38.5 \pm 13.5$ & $7.5 \pm 5.5$ & $46.2 \pm 10.8$ \\
\hline Physiotherapist & $\begin{array}{l}\text { Male } \\
\text { Female }\end{array}$ & $\begin{array}{l}4 \\
4\end{array}$ & $24.5 \pm 1.0$ & $5.3 \pm 0.9$ & $24.7 \pm 3.1$ \\
\hline Pharmacist & $\begin{array}{l}\text { Male } \\
\text { Female }\end{array}$ & $\begin{array}{l}1 \\
2\end{array}$ & $31.0 \pm 2.1$ & $5.3 \pm 1.0$ & $24.0 \pm 3.7$ \\
\hline
\end{tabular}

and interpret the thoughts of participants by repeatedly reading the original texts including the keywords that frequently appeared and with the keywords related to coping behaviors taken during the norovirus infection outbreak among all of the important keywords obtained by the text mining analysis. In this process, we made every effort to ensure the reliability and validity of the results of the analyses referring to and enlisting supervision by research experts.

\section{E. Ethical considerations}

Prior to the conduct of this study, we contacted the director of the hospital, nursing director, and head of the medical department, and requested their cooperation in this study in writing and referring to a leaflet entitled 'Invitation to a study Outline of the research'. The leaflet explains the purpose, methods, data management and storage, and ethical considerations for matters related to disadvantages and risks arising from the participation or cooperation in the study, stating that the participation or discontinuation of participation after consenting to participate are entirely voluntary, that refusal to participate will not result in any disadvantage to the participant, and that the privacy and personal information of the participants can and will be protected.

Further, as expected benefits of the participation and cooperation, it was stated that reviewing the norovirus infection outbreak and clarifying the details will contribute to records that will be useful to control infections and prevent their further spread. The leaflet also includes explanations about the handling of data after the end of the study. The participants expressed consent with a thorough understanding of these matters. Further, the study was conducted under approval from the Ethics Committee of the Faculty of Health \& Medical Care Saitama Medical University, Japan. There are no conflicts of interest to declare.

\section{RESULTS}

\section{A. Demographic characteristics of participants (Table 2)}

The mean age of the participants was $30 \pm 5.0$ years for nurses, $38.5 \pm 13.5$ years for physicians, $24.5 \pm 1.0$ years for physiotherapists, and $31 \pm 2.1$ years for pharmacists, the mean length of clinical experience was $7.8 \pm 5.3$ years for nurses, 7.5 \pm 5.5 years for physicians, $5.3 \pm 0.9$ years for physiotherapists, and $5.3 \pm 1.0$ years for pharmacists, and the mean length of interviews was $27.9 \pm 8.6$ minutes for nurses, $46.2 \pm 10.8$ minutes for physicians, $24.7 \pm 3.1$ minutes for physiotherapists, and $24.0 \pm 3.7$ minutes for pharmacists.

\section{B. Analysis by the text mining}

1) Importance and frequency of keywords appearing in the interviews with the professionals of the four staff categories (Table 3): We performed a keyword association analysis using the text mining tool "Trend Search 2008" (SSRI).

a) Nurses: A total of 367 keywords were extracted. The keyword most frequently appearing was the term <patient>, 124 times, and in 109 related text samples, <patient $>$ ranked in the second place in importance. <Remember> appeared 63 times, in 60 text samples, about half of that for <patient>, and the importance ranking was first. When going back over the original text samples, <remember> was counted together with "I remember" and "I do not remember". Next, $<$ do $>$, <understand> and <report> were all ranked in the top 5. Table 3 shows the top 50 of the 367 keywords.

b) Physicians: A total of 208 keywords were extracted. $<$ Patient $>$ ranked first in importance ranking and appeared 36 times in 28 related text samples. <Nurses> is in second place in importance and appeared 19 times in 15 related text samples, followed by <remember>, <do> and <information>. Table 3 shows the top 50 of the 208 keywords.

c) Physiotherapists: A total of 400 keywords were extracted. <Patient> ranked first in importance ranking and appeared 114 times in 94 related text samples. This frequency of appearance is considerably high when compared to <ward> which was in the second place in importance ranking and appeared 47 times. Physiotherapists frequently stated the term <ward>. The third place in importance ranking was <none>, which appeared 36 times. As the frequency of appearance of $<$ do >, which ranked fifth in importance ranking, was 45 times, the frequency of appearance and importance ranking of these two keywords were the reverse. The fourth place was $<$ responsible $>$. 
Table 3 Importance and Frequencies of Keywords on Coping Behaviors of Nurses, Physicians, Physical Therapists, and Pharmacists

\begin{tabular}{|c|c|c|c|c|c|c|c|c|c|c|c|c|c|c|c|c|}
\hline \multirow[b]{2}{*}{ Rank order } & \multicolumn{4}{|c|}{ Nurse $(\mathrm{n}=22)$} & \multicolumn{4}{|c|}{ Physician $(\mathrm{n}=4)$} & \multicolumn{4}{|c|}{ Physiotherapist $(\mathrm{n}=8)$} & \multicolumn{4}{|c|}{ Pharmacist $(\mathrm{n}=3)$} \\
\hline & Keyword & Importance & $\begin{array}{l}\text { No. of related } \\
\text { text samples }\end{array}$ & $\begin{array}{l}\text { Appearance } \\
\text { frequency }\end{array}$ & Keyword & Importance & $\begin{array}{l}\text { No. of related } \\
\text { text samples }\end{array}$ & $\begin{array}{c}\text { Appearance } \\
\text { frequency }\end{array}$ & Keyword & Importance & $\begin{array}{l}\text { No. of related } \\
\text { text samples }\end{array}$ & $\begin{array}{l}\text { Appearance } \\
\text { frequency }\end{array}$ & Keyword & Importance & $\begin{array}{l}\text { No. of related } \\
\text { text samples }\end{array}$ & $\begin{array}{c}\text { Appearance } \\
\text { frequency }\end{array}$ \\
\hline 1 & Remember & 17.059 & 60 & 63 & Patient(s) & 2.539 & 28 & 36 & Patient(s) & 8.084 & 94 & 114 & $\begin{array}{l}\text { Patient(s) } \\
\end{array}$ & 2.367 & 18 & 23 \\
\hline 2 & Patient(s) & 14.809 & 109 & 124 & Nurse(s) & 2.193 & 15 & 19 & Ward & 6.774 & 41 & 47 & Information & 2.195 & 9 & 11 \\
\hline 3 & Do: verb & 9.337 & 49 & 50 & Remember & 2.185 & 7 & 9 & None & 6.396 & 33 & 36 & Listen & 1.621 & 5 & 7 \\
\hline 4 & Understand & 8.321 & 29 & 29 & Do: verb & 2.120 & 14 & 16 & Responsible & 5.926 & 26 & 29 & Nurse(s) & 1.534 & 9 & 9 \\
\hline 5 & Report & 8.315 & 31 & 32 & Information & 1.728 & 7 & 7 & Do & 5.781 & 35 & 45 & Heard of & 1.520 & 7 & 7 \\
\hline 6 & Listen & 7.790 & 30 & 34 & Infection & 1.645 & 8 & 9 & Me & 5.629 & 24 & 24 & Suffer from & 1.479 & 6 & 7 \\
\hline 7 & Ward & 7.763 & 30 & 30 & $\mathrm{Me}$ & 1.568 & 11 & 12 & Information & 5.556 & 26 & 29 & Medicine & 1.434 & 7 & 8 \\
\hline 8 & Vomit & 7.719 & 37 & 37 & Report & 1.453 & 7 & 10 & Infection & 5.096 & 25 & 26 & Infection & 1.377 & 14 & 14 \\
\hline 9 & Look & 7.456 & 22 & 24 & Think & 1.428 & 11 & 13 & Rehabilitation & 4.984 & 33 & 38 & Do: verb & 1.332 & 6 & 6 \\
\hline 10 & Difficult & 7.286 & 16 & 17 & Awareness & 1.380 & 5 & 6 & Report & 4.819 & 20 & 23 & Understand & 1.274 & 5 & 5 \\
\hline 11 & $\mathrm{Me}$ & 7.003 & 26 & 27 & Speak & 1.375 & 7 & 8 & Remember & 4.751 & 14 & 16 & Physician(s) & 1.271 & 3 & 3 \\
\hline 12 & Think & 6.825 & 27 & 27 & Operation & 1.265 & 6 & 6 & Stay & 4.719 & 28 & 31 & $\begin{array}{l}\text { Nurse } \\
\text { administrator }\end{array}$ & 1.238 & 3 & 5 \\
\hline 13 & Rehabilitation & 6.509 & 23 & 23 & Physician(s) & 1.262 & 8 & 9 & Nurse(s) & 4.577 & 24 & 27 & Report & 1.177 & 3 & 4 \\
\hline 14 & Pharmacist(s) & 6.272 & 18 & 18 & Instruction & 1.249 & 3 & 3 & Speak & 4.467 & 31 & 35 & Tell & 1.160 & 3 & 3 \\
\hline 15 & Diarrhea & 6.238 & 24 & 24 & Give & 1.210 & 3 & 3 & Many & 4.174 & 17 & 19 & Vomit & 1.047 & 3 & 3 \\
\hline 16 & Heard of & 6.098 & 17 & 17 & Rehabilitation & 1.195 & 5 & 7 & Suffer from & 3.954 & 15 & 15 & Ward & 1.040 & 5 & 5 \\
\hline 17 & Tell & 6.077 & 21 & 21 & Can & 1.189 & 4 & 5 & Vomit & 3.948 & 16 & 17 & Influenza & 1.033 & 3 & 3 \\
\hline 18 & Isolation & 6.036 & 14 & 14 & Share & 1.164 & 4 & 4 & Perform & 3.834 & 17 & 22 & Prescription & 0.998 & 3 & 3 \\
\hline 19 & Manual & 5.734 & 14 & 14 & Ward & 1.150 & 4 & 4 & Person & 3.807 & 20 & 21 & Interaction & 0.990 & 3 & 3 \\
\hline 20 & Speak & 5.678 & 20 & 20 & Be involved & 1.140 & 4 & 5 & Enter & 3.404 & 15 & 17 & Story: Noun & 0.970 & 3 & 3 \\
\hline 21 & Come & 5.539 & 17 & 19 & Forget & 1.110 & 5 & 5 & Look & 3.064 & 12 & 13 & Remember & 0.934 & 2 & 3 \\
\hline 22 & Information & 5.513 & 18 & 18 & Listen & 1.107 & 3 & 5 & Understand & 2.943 & 9 & 11 & Work & 0.922 & 4 & 4 \\
\hline 23 & Share information & 5.390 & 13 & 13 & Tell & 0.982 & 3 & 3 & Physician(s) & 2.917 & 15 & 16 & Pharmacists & 0.894 & 4 & 4 \\
\hline 24 & In charge of & 5.291 & 15 & 15 & $\begin{array}{l}\text { Leave things to } \\
\text { someone }\end{array}$ & 0.959 & 2 & 2 & $\begin{array}{l}\text { Attending } \\
\text { physicians }\end{array}$ & 2.830 & 11 & 13 & Inform & 0.881 & 3 & 3 \\
\hline 25 & Night shift(s) & 4.733 & 9 & 9 & Discharge & 0.915 & 2 & 3 & Closed & 2.786 & 6 & 6 & Look & 0.868 & 3 & 3 \\
\hline 26 & Suffer from & 4.630 & 14 & 15 & Story & 0.886 & 3 & 3 & Listen & 2.727 & 10 & 11 & Fine & 0.810 & 2 & 2 \\
\hline 27 & Walker & 4.613 & 12 & 12 & Outpatient & 0.885 & 2 & 3 & Tell & 2.682 & 10 & 14 & Meet & 0.801 & 2 & 2 \\
\hline 28 & Spread & 4.363 & 12 & 14 & Ward chief physician & 0.884 & 2 & 2 & Come & 2.656 & 10 & 10 & Orthopedics & 0.801 & 3 & 3 \\
\hline 29 & Toilet & 4.184 & 11 & 12 & Touch & 0.849 & 3 & 3 & Collaboration & 2.593 & 8 & 11 & Other: noun & 0.721 & 3 & 3 \\
\hline 30 & Closed & 3.902 & 9 & 9 & Others: noun & 0.842 & 3 & 3 & Team & 2.548 & 11 & 11 & Working & 0.691 & 1 & 2 \\
\hline 31 & Physician(s) & 3.805 & 11 & 11 & Artificial joint & 0.792 & 3 & 3 & Heard of & 2.513 & 8 & 8 & None & 0.685 & 2 & 2 \\
\hline 32 & Disinfection & 3.721 & 11 & 11 & Look & 0.779 & 5 & 5 & Measures & 2.512 & 10 & 10 & Awareness & 0.682 & 2 & 3 \\
\hline 33 & What: pronoun & 3.547 & 12 & 12 & Types of occupation & 0.767 & 4 & 4 & Orthopedics & 2.481 & 8 & 9 & Speak & 0.675 & 2 & 2 \\
\hline 34 & Examination & 3.494 & 8 & 8 & Want & 0.740 & 3 & 6 & Appear & 2.433 & 10 & 11 & Duty & 0.675 & 2 & 3 \\
\hline 35 & Day shift(s) & 3.454 & 9 & 9 & Examine & 0.737 & 2 & 4 & Medical record & 2.330 & 7 & 7 & Walk & 0.662 & 1 & 2 \\
\hline 36 & Leader & 3.414 & 8 & 9 & Suffer from & 0.674 & 2 & 2 & Wash hands & 2.305 & 10 & 10 & Confirm & 0.640 & 2 & 2 \\
\hline 37 & Others: noun & 3.107 & 8 & 8 & Risk & 0.661 & 3 & 3 & In charge of & 2.302 & 7 & 7 & Agree & 0.635 & 1 & 1 \\
\hline 38 & Room & 3.086 & 9 & 9 & None & 0.643 & 4 & 5 & Awareness & 2.262 & 9 & 9 & Ask & 0.634 & 2 & 2 \\
\hline 39 & See & 2.818 & 7 & 7 & Drip & 0.639 & 1 & 1 & Take & 2.253 & 10 & 10 & Meeting & 0.623 & 2 & 2 \\
\hline 40 & Apron & 2.764 & 5 & 8 & Resident(s) & 0.615 & 1 & 2 & Orthopedics & 2.174 & 10 & 10 & Ward closed & 0.618 & 2 & 2 \\
\hline 41 & Awareness & 2.751 & 8 & 8 & The same team & 0.606 & 2 & $\sqrt{2}$ & Training & 2.165 & 10 & 11 & Night shifts & 0.612 & 2 & 2 \\
\hline 42 & Procedure & 2.715 & 6 & 6 & Team & 0.601 & 2 & 2 & Connsultation & 2.139 & 7 & 11 & Nurse station & 0.605 & 2 & 2 \\
\hline 43 & Infection & 2.639 & 8 & 9 & Study meeting & 0.599 & 3 & 3 & Cancellation & 2.085 & 6 & 8 & $\begin{array}{l}\text { Preventive } \\
\text { prescription }\end{array}$ & 0.595 & 2 & 2 \\
\hline 44 & Work & 2.620 & 6 & 6 & Important & 0.597 & 3 & 3 & Fine & 2.082 & 6 & 7 & Finish & 0.586 & 1 & 2 \\
\hline 45 & Inform & 2.618 & 6 & 6 & Changing ward & 0.597 & 2 & 2 & Feel & 2.064 & 11 & 11 & Same name & 0.577 & 2 & 2 \\
\hline 46 & Private Room & 2.599 & 7 & 7 & Problem & 0.589 & 2 & 3 & Study meeting & 1.994 & 7 & 7 & Many & 0.575 & 1 & 1 \\
\hline 47 & Use & 2.557 & 4 & 7 & Face & 0.587 & 2 & 2 & Think & 1.976 & 8 & 8 & Teach & 0.570 & 1 & 3 \\
\hline 48 & Give & 2.510 & 5 & 5 & Clearly & 0.587 & 2 & 2 & Meeting & 1.939 & 5 & 5 & Special & 0.554 & 1 & 1 \\
\hline 49 & Foods brought in & 2.505 & 7 & 7 & Understand & 0.585 & 2 & 3 & In: noun & 1.905 & 6 & 6 & Drink & 0.549 & 2 & 2 \\
\hline 50 & Record & 2.499 & 7 & 7 & Isolation & 0.565 & 1 & 1 & Go & 1.854 & 7 & 7 & Take notes & 0.532 & 1 & $\frac{1}{2}$ \\
\hline
\end{tabular}


d) Pharmacists: A total of 168 keywords were extracted. $<$ Patient> ranked first in importance ranking and appeared 23 times in 18 related text samples. <Information> ranked second in importance ranking and appeared 11 times in 9 related text samples. <Infection> appeared 14 times and was in the third place in frequency of appearance, but ranked eighth in importance ranking. Other higher ranked keywords include $<$ listen>, <nurses>, and <know>.

2) Concept mapping up to 50 important keywords obtained by the keyword association analysis: The keywords involved in the mapping are the keywords that are ranked in the top 50 by the keyword association analysis. The closeness of the distance between keywords is shown by the thickness of the connecting line, indicating a higher relevance.

a) Characteristics of concept mapping of the nurses (Figure 1): In the mapping of important keywords, three groups were formed by <memorize>, <communicate>, and < in charge of $>$ with the keywords "patients" as the center. The keyword <remember> was visualized as being explained by <difficult>, <night shift>, < closed>, and <ward>. The keyword <report> was linked to <rehabilitation>, < pharmacists>, and <physicians>, all relating all of the occupations investigated in this study. The related text samples include "I remember the ward closed due to norovirus", "I remember patients were in a room for three", "I do not remember patients infected by norovirus, but I remember that the number of infected patients increased one by one, I felt 'Oh this patient too? It happened in no time at all ", "I remember only that it was difficult to handle", "I do not remember whether patients I was in charge of were infected", "I saw patients who threw up, but I do not remember which patients it was", and "I do not remember who the infected patients were, at all'.

The keyword <communicate> was linked to <leader> and <information>, and the related text samples included "I informed the leader nurse that day of the symptoms of the patient", "I reported the information as a leader, but have no recollection of urgently communicating the information to other nurses", "I did not communicate the information to and did not specifically collaborate with other professions", and "I could not study the medical records when I was busy. I looked at medical records as information collection before starting the day shift. I kept records of what I did, but only much later because I can do it only when I have time". <Report> was strongly linked to the <physician>, <rehabilitation>, and <pharmacists>, and <share information> and <listen> were closely associated. Related text samples for these include "I did not report the information specifically to staff in rehabilitation", "I was asked what happened by rehabilitation staff", "I did not report (or remind anybody of) the information of symptoms such as vomiting to the rehabilitation staff and pharmacists", and "I reported the patient symptoms to the physician (or attending physician) immediately and I was told to wait and see a little longer", "I heard it in a sharing of information meeting when I came to work", "I do not know what happened after I had passed the information along", and "I reported the information about patients in a sharing of information meeting the following day". Team medicine is defined as "providing medical services accurately and in a manner suitable to the conditions of patients determined through mutual collaboration and complementarily among different medical professionals while sharing purpose and information in performing different assignments based on their (staff) high (specialized) expertise" [1]. Multidisciplinary collaboration is indispensable because infection control cannot be realized without the involvement of all participants in the team. It is also reported that the key persons in team medicine are the nurses [1]. In the present study, the keyword <report> was linked to<rehabilitation>, <pharmacists>, and <physicians>, as shown in the concept mapping of the nurses (Figure 1). In the concept maps of the other occupations (Figures 2, 3, and 4), the keyword <nurses> places at the center of the maps, and is linked to <report>. This illustrates that the physicians, physiotherapists, and pharmacists in the participating hospital expect nurses to play the role of reporter of information, suggesting that nurses are considered the most effective staff category when working to integrate the contributions of different professionals.

b) Characteristics of the concept mapping of the physicians (Figure 2): There were <nurses> and <patients> at the cores of the concept mapping of the physicians. $\langle$ Nurses $>$ was linked to $<$ leave something to nurses >, <information>, and <share>. The related text samples include "Whether nurses can or cannot deal with it varies with the ability of the nurses. That's why the matters I leave undone differ", "I want to leave infection prevention to the nurses rather than I do it myself", "I want patient information about pain and fever, especially about the symptoms of wound infections", and "I think that nurses are doing well. Their work is hard, I thought". In <patient $>$, the terms <remember>, <clearly>, and <face> were closely associated.

Also, <instruction>, <give >, and <drip> were closely associated. The related text samples for these include "The nurse told me that the patient is vomiting, but I thought we should wait and see before intervening. But the nurse told me that the vomiting would not stop, so I gave instructions to administer drip", "Of course I clearly remember the name and face of the patient", "I moved my patients to another ward as soon as I heard that norovirus infections had occurred at the ward", "I had another ward take care of my patients until the norovirus outbreak was over", "I clearly remember the patients", "I cancelled the admission of new patients and surgery because I decided that I was not able to leave my patients to nurses in other wards", "I discharged patients who I thought were able to manage", "I never forget patients especially patients with artificial joints because we will see them for the rest of their lives, though there are some patients we only see once a year", "My patients rely on me very much. They tell me not to leave the hospital because they know physicians of university hospitals often change hospitals". "My patient was also infected. The patient underwent surgery on the lumbar spine, and had just begun to walk with a corset using a walker. Was scheduled to have an outpatient visit the next day. But he may have forgotten that he suffered from norovirus, because he is a bit careless", and "I did not give instructions for isolation. I did not go to the ward". 


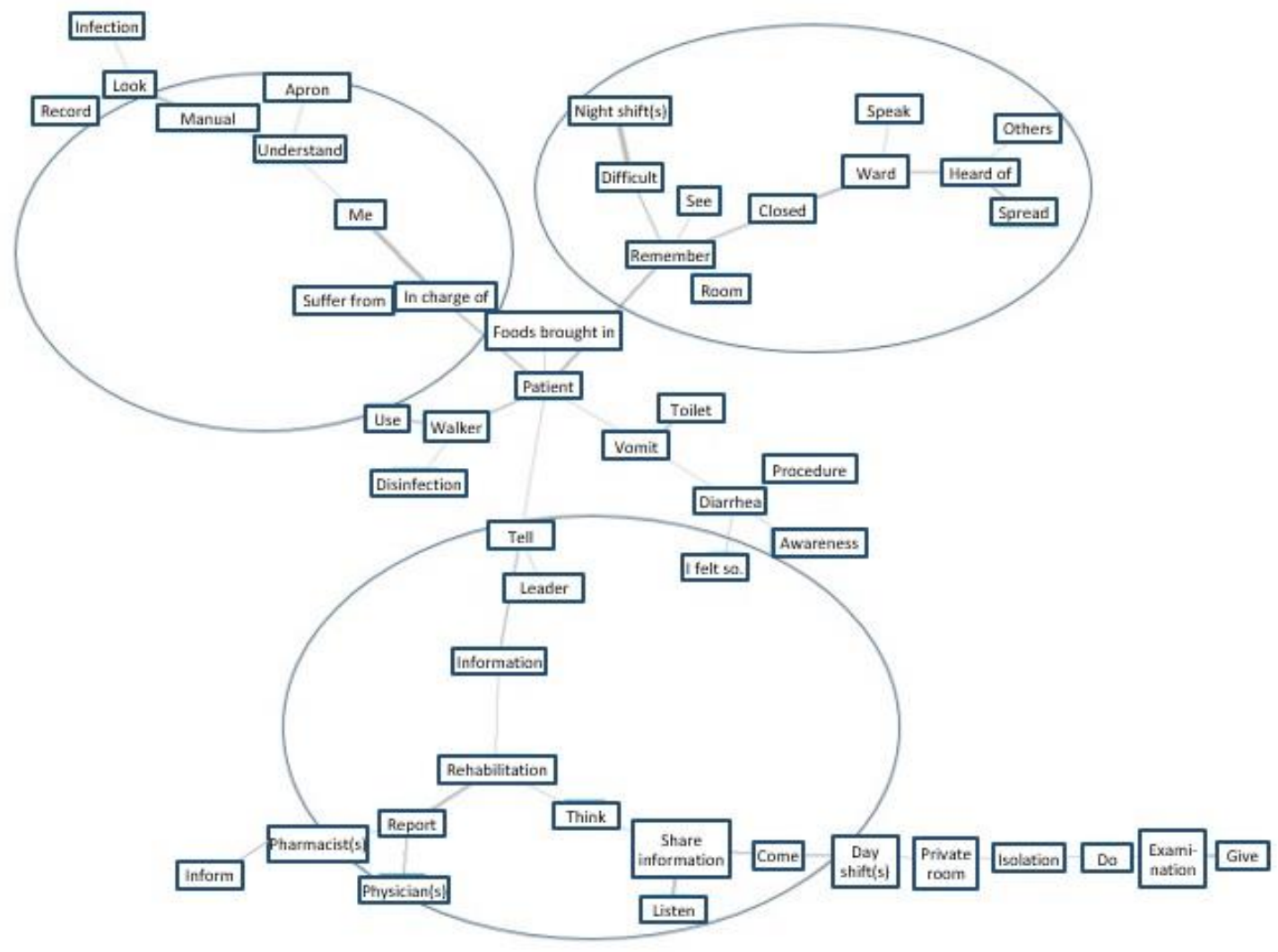

Fig. 1 Coping behaviors of nurses at the time of the norovirus infection outbreak

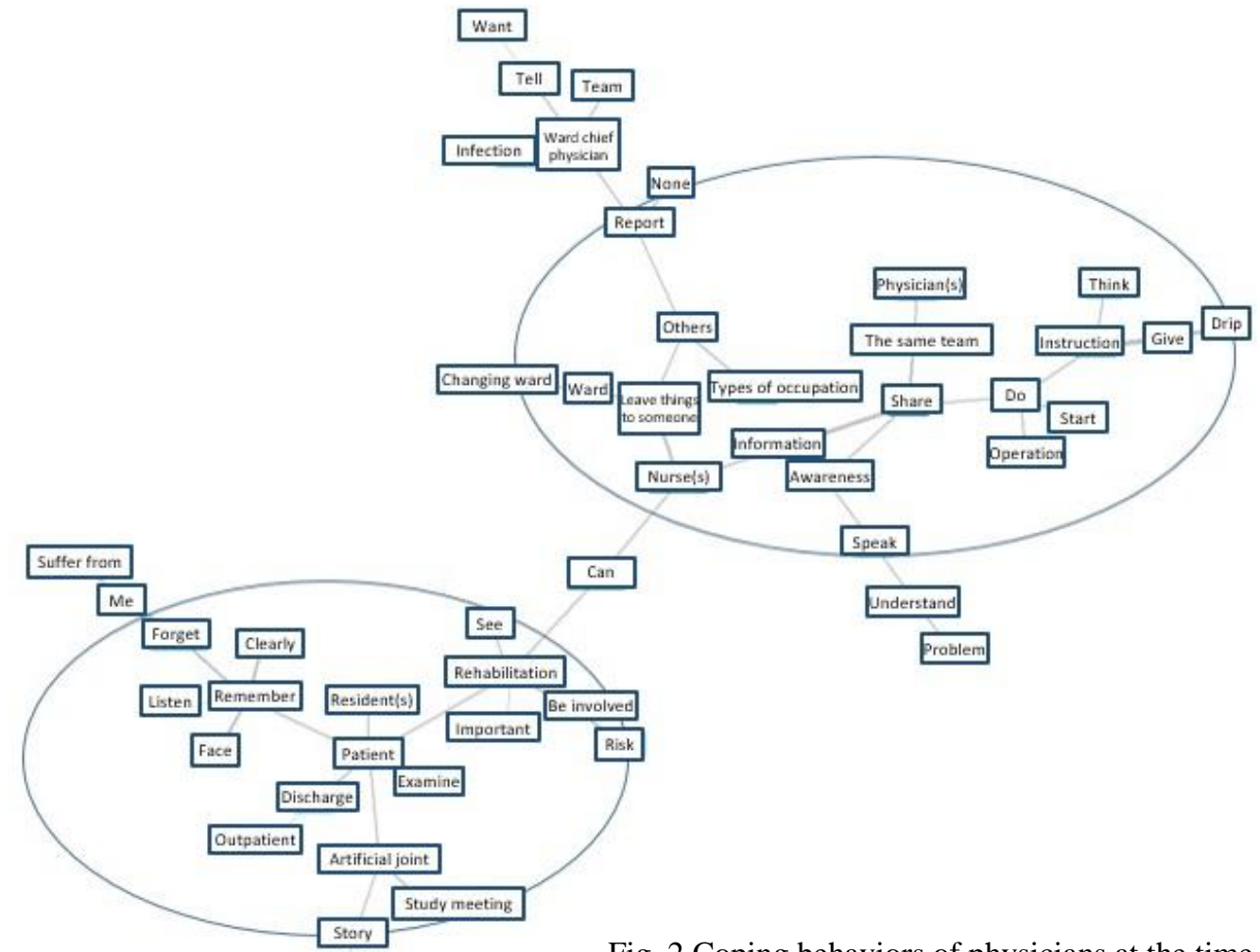

Fig. 2 Coping behaviors of physicians at the time of the Touch norovirus infection outbreak 


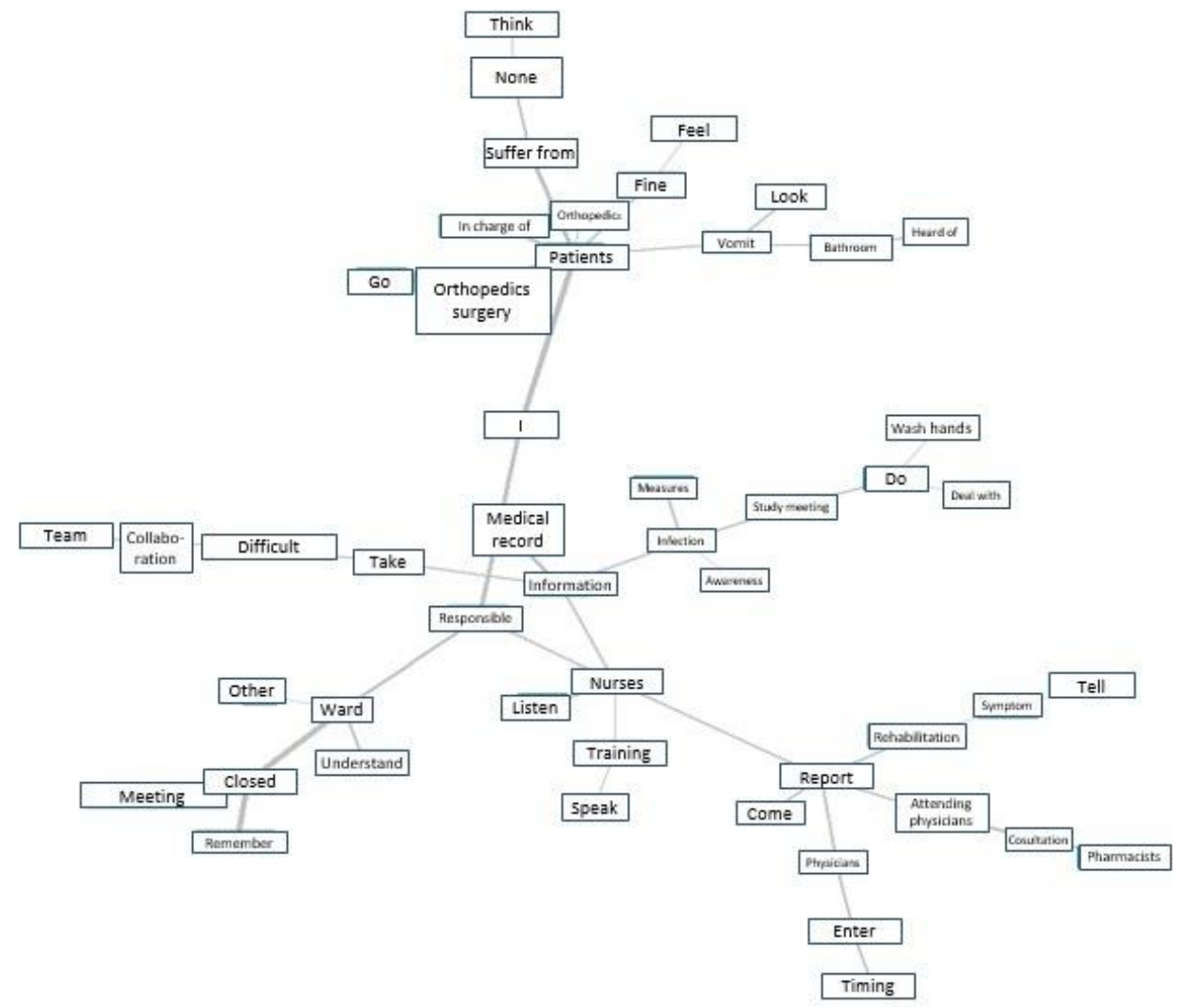

Fig. 3 Coping behaviors of physiotherapists at the time of the norovirus infection outbreak

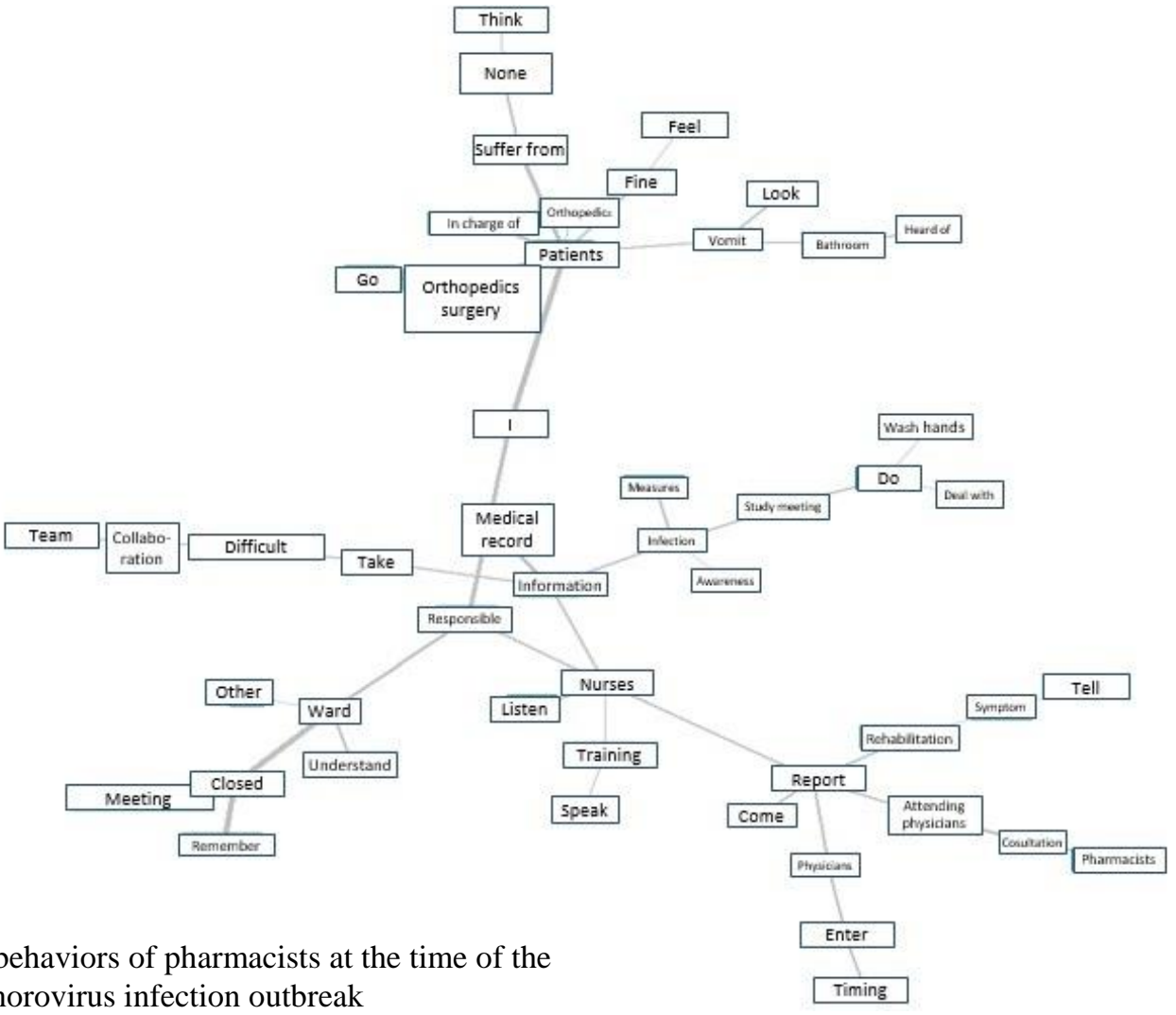

Fig. 4 Coping behaviors of pharmacists at the time of the norovirus infection outbreak 
c) Characteristics of the concept mapping of the physiotherapists (Figure 3): In the mapping of important keywords, three groups were formed by <patients>, <responsible>, and <report> as the centers. <Patients> and $\langle$ responsible $\rangle$ were closely associated with $\langle\mathrm{I}\rangle$. The related text samples include "I clearly remember the outbreak because one of the patients I was responsible for suffered from norovirus" and "Every morning I receive information about patients I am responsible for on the day through the electronic medical records and the physiotherapist previously in charge". <Patients> was linked to <suffered from> and < in charge of >. The related text samples include "I hurried to the ward because a patient I was in charge of said that he had vomited the other day", "Staff in charge of other wards expressed a sense of crisis about the norovirus, but I did not feel it was critical because patients in my ward were fine, and I did not think it so difficult to deal with norovirus even at the time of the outbreak", and "Patients in other wards pay more attention to their health, and frequently wash their hands". $<$ Responsible> and <report> are linked through the keyword $<$ nurses $>$, and the related text samples include "I hesitated to ask nurses questions because they looked busily running and performing their duties", and "Nurses in charge of me change daily, and I feel as if I could not see my nurse for days because they have nightshifts". $<$ Responsible $>$ is linked to $<$ medical record $>$ and $<$ ward $>$. The related text samples include "Every morning I receive information about patients I am responsible for on the day through the electronic medical records and the physiotherapist previously in charge $\rangle$. <Report $\rangle$ is linked to <attending physicians> and <physician>, and the related text samples include "If my patient shows symptoms of illness during rehabilitation, I will report it to the ward of the patient, but I will not if it is the patient who is doing rehabilitation next to my patient", and "At that time, I received no report from physicians and nurses".

d) Characteristics of the concept mapping of the pharmacists (Figure 4): <Patients> and <information> are connected by the keyword $\langle$ physicians $>$, forming one group. Also, <nurses $\rangle$, <listen $>$, and $\langle$ do $>$ form one group. $\langle$ Do $\rangle$ is linked to $\langle$ talk $\rangle$ and $\langle$ meeting $\rangle$, and the related text samples include "Because nurses in this ward often talk among themselves, we relatively easily get detailed information", and "Because I have too many things to do, I have to devote myself to my assignment. I have no time to talk". The keyword <patients> is linked to <fine> and <vomiting>, but the keywords rehabilitation and physiotherapist did not appear.

\section{DISCUSSION}

\section{A. Characteristics and problems with coping behaviors, by occupation}

\section{1) Nurses}

a) Absence of information sharing among the staff in the same occupation and with staff in different occupations: In this study it was found that nurses and physicians adopted different coping behaviors during the norovirus infection outbreak, and that there are differences among the different work categories. Some nurses immediately communicated the symptoms and conditions of patients to the attending physicians, and others communicated this to the leader nurses of the day. Then, the information was communicated from the leader nurses to the head nurse of the ward or the nurse providing links to the rest of the hospital. Nurses did not share their commonly gained understanding through opportunities such as conferences, but learned of the information through communication in the form of messages between staff members. Consequently, the information was not formally communicated at the meetings the following day, and was not reported to the nurses and physicians who were not in charge on the day when norovirus infection outbreak (cases) was identified. This suggests that there may have been more nurses who were on duty without knowing the information than there were nurses who knew the actual situation. From the related text samples: "I cannot survey medical records when I am busy. I see medical records before starting the day shift to know the situation. I kept records of what I did, but only much later because I can do it only when I have time" show it is not surprising that the information is not shared unless the nurses who communicate the information employ some means for ensuring that the information will reach the other party. There were no nurses who were critical about the infection spreading when the information was not communicated immediately. This may be a factor resulting in the spread of the infection. Similarly, the lack of a sense of crisis may have caused nurses not to communicate the information to other staff.

Onishi et al. have reported that the hospital started to respond to the outbreaks three days after the first onset, but at that time the infection had spread through the whole of the floor [11]. Yamashita et al. stated that it is possible to avoid restricting the admission of new patients if patients with infectious gastroenteritis were isolated on the day of the onset [6]. Other studies also report the usefulness of a speedy response [12.13]. Communicating information about infections promptly, sharing the information among all health care workers, and responding to deal with the infection will be an important factor to prevent and limit outbreaks. For this purpose, it is necessary to improve information display methods to make the information other than the electronic medical records instantaneously and visibly accessible.

b) Problems due to the characteristics of the duties of nurses: The nurses clearly remembered that the ward was closed. They also relatively clearly remembered the happenings and responses on the day of the start of the infection, including that large numbers of patients vomited and complained of symptoms such as diarrhea, and that they worked hard on the repeated disinfection of wards every two hours. However, the nurses did not remember whether the patients suffering from norovirus infection were patients they were responsible for although the ward used Primary Nursing where the same nurses are engaged with the same patients from admission to discharge. They remembered little of whether the affected patients had undergone surgery already, or why patients were hospitalized. 
In the mapping, <remember> was linked to <ward>, <closed>, and <difficult>, and the <difficult> was strongly connected with <night shifts>. It would seem that this is influenced by the characteristics of the duties of nurses. Nurses provide care for 24 hours in 3 shifts, unlike other occupations. As illustrated by the related text samples of the nurses: "I do not know what happened after I have communicated the information" and of physicians "I do not often ask nurses about patients because whatever I ask them, they say they were not in charge of the patient on that day, they were not on duty, or it was the first day after the holidays", nurses who were responsible for the assigned shift did their best to protect the ward, but they may not have had a sense of responsibility for individual patients, unlike the case with physicians. The related text sample of nurses that "I do not remember", suggests the possibility that they did not review cases properly. It can be inferred that reviewing cases repeatedly will enable nurses to respond to emergencies such as future outbreaks although the correlation between nurse clinical skills and the length of the nursing experience cannot be assumed [14.15].

\section{2) Physicians}

a) Sense of responsibility of attending physicians towards patients: When physicians first heard of the symptoms of patients, they gave instructions for drips, stool cultures, and examination of stools. This indicates that physicians acted speedily when they suspected infection. They also had discussions in the medical staff team, and decided to cancel the hospitalization of patients and to postpone surgery. In some cases, physicians moved their patients to other wards or performed surgery in the operation rooms of other wards. Due to the characteristics of the duties of physicians, they are in a position to be able to make decisions. This may relate to their speedily taking action, and is quite different from nurses who act after being instructed.

The physicians clearly remembered the conditions of their patients, such as whether the patients in their charge were infected by the norovirus. In the concept mapping, there is a large cluster of keywords with "patient" as the core, where the keywords <remember>, <face>, and <clearly> are strongly associated with each other. As illustrated by the related text samples such as "I will never forget about my patients", "I have been in charge of the patients since they were outpatients, and I will see them for the rest of their lives", and "I will respond to the expectations of my patients who leave me to perform the surgery", show that they always pay close attention to their patients. These suggest that physicians have a strong sense of responsibility towards their patients.

b) Not seeing the situation of the entire ward: Physicians gave instructions for drips and examinations at the onset of the norovirus infection, but they did not go to the ward to check on the patients, nor gave instructions for isolation. However, patients feel a sense of security just by having consultation with physicians, leading to early detection of the abnormal situations. Further, the nurses were pressed by work when providing care during the emergency. Physicians have to give appropriate instructions from a different viewpoint from that of nurses to prevent infection from spreading. The physicians in the ward in this study responded to their patients responsibly, but they did not see the entire ward. Ideally, physicians should pay attention to the entire ward at the occurrence of infectious diseases in wards and in emergencies.

\section{3) Physiotherapists}

a) Absence of new information shared: The statement "Every morning I receive information about patients I am responsible for on the day through the electronic medical records and the physiotherapist previously in charge" shows that physiotherapists collect information about patients mainly from the electronic medical records, suggesting that physiotherapist start their assignment without knowing what happened during the nightshift if it is not entered in the record. For nurses at nightshifts responding to patients is a top priority, and they may not enter what happened during the nightshift in a timely manner in the electronic medical record. The statements "I hurried to the ward because a patient I was in charge of said that he had vomited the other day" and "At that time, I received no report from physicians and nurses" show that physiotherapists may not have immediately grasped the information on the outbreak of norovirus. Before rehabilitation, the staff in charge of infection contacts the ward, confirms what is happening in the ward, and informs everyone involved of the new developments and this may be one effective measure to ensure transmission of occurrences.

\section{4) Pharmacists}

a) Lack of communication with other occupations due to heavy workload: The statements "Because I have too many things to do, I have to devote myself to my assignment. I have no time to talk" and "I cannot consider my duties over just because it is time to do so, and I have to wait for prescriptions from physicians" show that pharmacists feel they are too busy due to their heavy workload. The pharmacists here were in a rush with duties that they had to finish on that day, without thinking about sharing information and collaborating with other occupations, and communication with other occupations was insufficient. Also, unlike nurses, physicians and physiotherapists, pharmacists have no patients they are especially in charge of. Because the pharmacists in the ward have to grasp the conditions of all the patients in the ward without contact with others, they are required to seek simple ways to collect the minimum necessary information, and for this purpose, sharing information with other occupations is important.

b) Collaboration between nurses and other occupations during the outbreak of the norovirus infection: The findings of the present study suggest an absence of appropriate infection control in the collaboration among different occupations during the norovirus infection outbreak. Nurses were unable to communicate the information to other occupations because they were pressed by work duties in providing care for patients and because they were unable to anticipate the spread of the infection at the onset of the infection. Nurses also reported, "I usually do not care about cooperation with other occupations", "I think that the pharmacist is doing a different 
job than mine, and I do not know what they are doing, but they always work busily till late", and "I am afraid of physicians, so I talk with them only when it is necessary". As infection control requires speedy "communication" of information to all medical staff involved in patient care, it is reported that the communication skills of nurses will influence the outcomes $[16,17]$. It is necessary to make efforts to communicate with other occupations and to establish trusting relationships.

To make collaboration between nurses and staff in other occupations effective require both sides to understand and have an awareness of issues and the sense of values that the individual person has. Due to the characteristics of their duties, physicians are in contact with other occupations mainly when they need to give instructions. In the concept mapping of the physician data (Figure 2) the keyword <information> is strongly associated with the keyword <sharing>, the <sharing> is linked to <the same team> and <physicians>, and they are closely associated with each other.

\section{CONCLUSIONS}

(1) At the norovirus infection outbreak, it was found that the nurses communicated information mainly at sharing of information at meetings and did not transmit the information to the entire ward or to staff in other occupations. There was a lack of communication with other professions as it is practiced in times where there are no emergencies.

(2) In the ward, there was no team collaboration for infection control. Rather, the employees were working individually even in the same occupation, and no team effort played a role. First of all, it is necessary to create a team consciousness among all staff in the same occupation, and to collaborate and share information within the team.

(3) In concept mappings of physicians, physiotherapists, and pharmacists, the keyword <nurses> places in the center of the maps, and is linked to <information> and <report>. Because the nurse plays a central role to report information among the four occupations, nurses should be aware of and assigned to play the role to coordinate team collaboration.

\section{ACKNOWLEDGMENT}

We wish to thank all the director of the hospital, nursing director, and head of the medical department, nurses, and physicians of the participating hospital for their help in participating in the present study.

\section{REFERENCES}

[1] Ministry of Health, Labour and Welfare, "Promotion of team medicine (Chiimu iryono suishin ni tsuite in Japanese)", 2011, http://www.mhlw.go.jp/shingi/2010/03/d1/s0319-9a.pdf, Accessed on September 15, 2017.

[2] Ministry of Health, Labour and Welfare, "Report of meeting to study promotion of team medicine (Chiimu iryo suishinni kansuru kentoukai nit suite houkokusho in Japanese)", 2011, http://www.mhlw.go.jp/shingi/2010/03/s0319-9.html, Accessed on September 15, 2017.

[3] A. Furukawa, Y. Ozaki, K. Kito, T. Sasaki, T. Nagao, K. Kitamura, et al., "Norovirus outbreaks in a university hospital (Daigaku byouindeno noro uirusuniyoru kansensei ichoen autobureikuno keiken in Japanese)", Bulletin of Shiga University of Medical Science, vol. 21(1), pp. 15-19, 2008 .

[4] S. Horikawa, N. Tadasa, K. Hirahara, H. Ito, S. Norisue, and T. Harada, "Study of outbreak of infectious gastroenteritis due to norovirus (Noro uirusuniyoru kansensei ichoen shudan hasseijireino kentou in Japanese)", Journal of the Japanese Association of Rural Medicine, vol. 57(1), pp. 16-21, 2008.

[5] S. Korte, A. Pettke, A. Kossow, A. Mellmann, S. Willems, and F. Kipp, "Norovirus outbreak management: how much cohorting is necessary", Journal of Hospital Infection, vol. 92(3), pp. 259-262, 2016.

[6] H. Yamashita, R. Oyamada, N. Oku, M. Nishimura, and N. Ishiguro, "Early isolation of patients suffering from infectious gastroenteritis and prevention of a nosocomial outbreak: an observational study (Kansensei ichoenkanjyano souki kakurito innai shudankansen kaihini kansuru kansatsu kenkyu in Japanese)", Japanese journal of environmental infections, vol. 27(5), pp. 333-334, 2012.

[7] K. Kikuchi, Y. Ohkusa, T. Sugawara, K. Taniguchi, and N. Okabe, "Preliminary trial of syndromic surveillance to early detection of nosocomial infection outbreak (Innai kansen souki tanchino tameno syoukougun surveillanceno kisoteki kenkyu in Japanese)", Journal of the Japanese Association for Infectious Diseases, vol. 81, pp. 162-172, 2007

[8] N. Murata, S. Kogi, and Y. Takayama, "Text mining, learning from cases (Jireide manabu tekisuto mainingu in Japanese)", Kyoritsu Shuppan Co., Ltd. Tokyo, 2008.

[9] T. Ito, "Textmining as a method for critical psychology: An alternative to variable psychology (Hihan shinrigakuno houhoutoshiteno tekisuto mainingu - hensuu shinrigakuni taisuru orutanathibu in Japanese)", The Japanese journal of psychological science, vol. 32(2), pp. 31-41, 2011.

[10] T. Ito, "Text mining as a tool for nursing studies (Tekisuto maininguno kangokenkyu ni okeru katsuyo in Japanese)", Japanese journal of nursing research, vol. 6(5), pp. 475-484, 2013.

[11] T. Onishi, M. Adachi, "Norovirus outbreaks in a teaching hospital: The role of infection control (Kyoikubyoinni okeru ichoen autobureiku eno taio in Japanese)", Journal of the Japanese Association for Infectious Diseases, vol. 81(6), pp.689-694, 2007.

[12] I. Idota, H. Hidai, K. Kikuchi, H. Yamaura, K. Totsuka, "Hospital outbreak of viral gastroenteritis attributed to norwalk-like viruses in Japan (Nowokuyo uirusuni kiinsuru kyusei ichoenno innai shudan hassei jireini tsuite in Japanese), Journal of the Japanese Association for Infectious Diseases, vol. 76(1), pp.32-40, 2006.

[13] Y. Takami, S. Kurihara, M. Tsukamoto, and A. Yasuoka, "Secondary infection among nursing staff following food-born norovirus outbreak in a hospital and the association with patient care (Noro uirusu innai shudan shokuchudokuni yoru kangoshokuinno nijikannsen hasseito kanjyakea jyoukyoutono kanren in Japanese)", Japanese journal of environmental infections, vol. 25(1), pp. 27-31, 2010.

[14] A. Kikuchi, "The relationship between professional autonomy in nursing and nurses' work environment and consciousness. The comparison with three groups of years of experience in nursing (Kango senmonshokuni okeru jiritsuseito shokubakankyo oyobi shokumuishiki tono kanren. Keiken nensugotoni mita hikaku in Japanese)", Japanese journal of nursing research, vol. 32(2), pp.92-103, 1999.

[15] R.Naito, N.Saito, M. Masako, "Acquisition condition of clinical practice skills of nurses (Kangoshino rinsho jissennryokuno kakutoku jyokyo in Japanese)", Journal of the Japan Nursing Society nursing management, vol.35, pp.280-282, 2004.

[16] S. Yasunami, "Awareness of specialized practices for infection control and influencing factors among certified expert nurses (Nintei kangoshiga ninshikisuru kansenkanrino senmonteki jissento sono eikyo youin in Japanese)", Japanese journal of environmental infections, vol. 29(3), 2014 .

[17] T. Azuma, M. Kamiya, M. Okazaki, and K. Endo, "Difficulties felt by nurses practicing team medical care in conducing cooperative and collaborative work (Chiemuiryouwo jissenshiteiru kangoshiga kanjiru rennkei kyoudouno konnan in Japanese)", Bulletin of Konan Women's University, vol.7, pp. 23-31, 2013. 


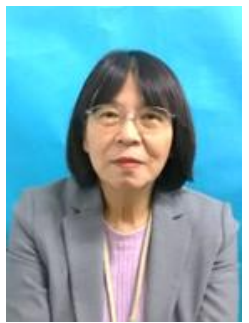

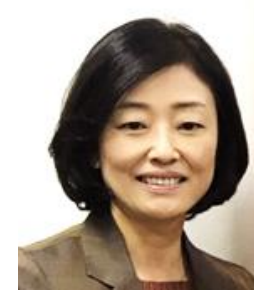

Assistant Professor Takae Machida master's degree of Nursing management. SAITAMA MEDICAL UNIVERSITY,Japan

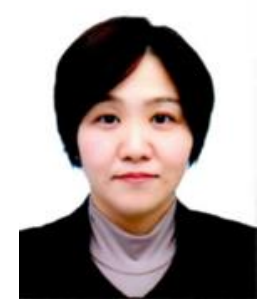

Ms. Hiroe Yanahara, obtained her Bachelor of Science in Nursing at Kurume University in 1998 and passed the Nursing and Public health nursing Licensure Examination on the same year. After working in a hospital for 9 years she worked as a public health nurse and a visiting nurse. She currently teaches Home Care Nursing at Shumei University.

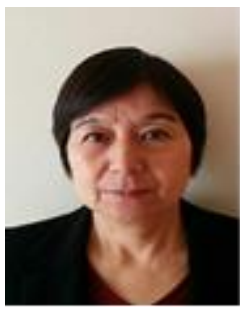

Hitomi SETOGUCHI Shumei University Faculty of Nursing
Ms Sachie Tomita, completed doctoral degree at the International Medical Welfare University Graduate School She currently teaches Fundamental Nursing at Faculty of

Health \& Medical care, Saitama Medical University.

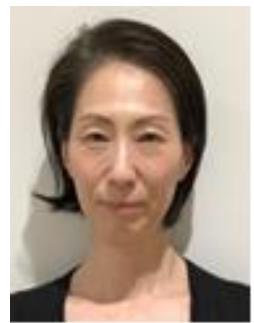

Ms. Kyoko Sato, obtained her acquired Nursing Licensure 1988. After working in a university hospital for 27 years.

Certified nursing administrator. Master of Business Administration (MBA). She currently teaches Adult Nursing at Shoin University.

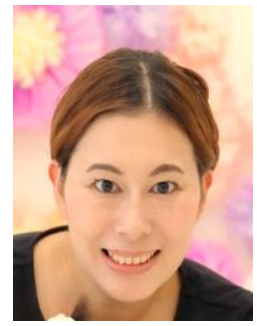

Asakura Chihiro

Yokohama Practical Vocational School. Research area is Mental Health.

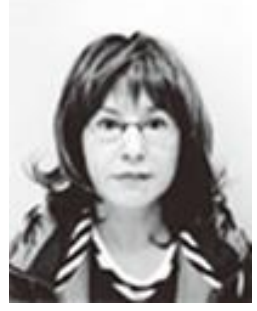

Ms. Eiko Suzuki, obtained her Phd of Science in Nursing at Tokyo Medical and Dental University. She currently professor at International University of Health and Welfare Graduate School. 